\title{
SIXTH COMMONWEALTH ENTOMOLOGICAL CONFERENCE
}

$\mathrm{A}^{\mathrm{T}}$

T the Sixth Commonwerlth Entomological Conwere fifty-five delegates, a greater number than ever before, and these included representatives from nearly all the countries of the British Commonwealth. The open meetings attracted a large attendance of entomologists from Britain and overseas, and a wide field of subjects was discussed.

The principal advances in economic entomology continue to be in the development and application of synthetic insecticides and in the study of problems arising from their use. Dr. H. G. H. Kearns (University of Bristol Fruit Research Station) reviewed the synthetic insecticides used on field crops and the methods of applying them. It is more difficult to treat field crops than plantation or orchard crops, and the margin of profit limits what can be done. These considerations apply particularly to peasantgrown crops, for which dusting, though an inefficient way of using toxic materials, has the advantage of requiring no water and of permitting the use of simple equipment.

The application of insecticides from aircraft was dealt with first by Mr. D. Yeo (Colonial Insecticides Research Unit, Tanganyika), with particular reference to tsetse fly. Methods using residual deposits are not economic against species spread through savannah woodland; but in large-scale experiments using 'space sprays' that deposit toxic droplets directly on the fly kills approaching 100 per cent have been reached. The behaviour of droplets of such a size (about $50 \mu$ ) that they neither impact on the canopy nor fail to settle is greatly affected by atmospheric turbulence: application is thus restricted to brief periods around dawn and dusk, when conditions are still, and this renders the use of aircraft uneconomic. Dr. R. C. Rainey (Desert Locust Survey) discussed developments in spraying flying locust swarms from aircraft. Methods of graphical analysis of the factors involved, together with laboratory indications that locusts are far more susceptible to insecticide when flying than when resting, have provided the background to aerial attacks on swarms recently invading East Africa. By bringing together data from many sources, estimates of efficiencies and costs have been obtained which suggest that the method is not seriously more expensive than hopper-baiting, to which it is complementary, making it possible to attack locusts throughout their life-cycle.

Dr. A. M. Massee (East Malling Research Station) illustrated the effect of insecticides on the balance of animal populations by the history of certain orchard pests. The mite Metatetranychus ulmi became a serious pest after the adoption of tar-oil washes, which are non-toxic to its winter eggs but killed many of its predators that hibernate on the tree, and the use of DDT and organo-phosphorus compounds made matters worse. DDT also favours woolly aphis, Eriosoma lanigerum, by destroying its parasite, Aphelinus mali; on the other hand, it has virtuedly eliminated the apple capsid, Plesiocorus rugicollis, which had become an important pest under the previous spray programme. Spider mites can now be controlled by summer ovicides that are relatively harmless to beneficial insects and mites; this advance underlines the need for more selective rather than more toxic insecticides.
In opening the discussion on the development of resistance to insecticides, Dr. J. R. Busvine (London School of Hygiene and Tropical Medicine) said that authentic cases, among which pests of medical importance preponderate, are mostly of recent occurrence, and it is not clear whether this results from a more widespread use of insecticides or from the way the modern ones act. The possibility and speed of development of resistance depend on the frequency of occurrence and effectiveness of resistant genes in the original population, the intensity of selection and the rate of reproduction. Little is known of the mode of action of resistance : one mechanism appears to be the conversion of toxic to innocuous compounds; but another one, differently inherited, is required to explain resistance to 'knock down'.

Dr. I. Thomas (Plant Pathology Laboratory, Harpenden) opened the discussion on the estimation of losses from pests by referring to early work based on mechanical simulation of damage, and then outlined the methods used in Britain by the National Agricultural Advisory Service, under the guidance of the Pest Assessment Committee. He emphasized that pest damage is only one of several factors affecting crop yields and that, especially in under. developed countries, it may not be the limiting one. His colleague, Mr. A. H. Strickland, described in more detail the use of insecticides to obtain differences in pest density on experimental plots. Regressions of yield on infestation thus obtained for each district can be integrated with rapid district-wide assessments of infestation to provide valid estimates or even forecasts of yield losses. A subsidiary development is the collation of pest densities with ecological features, thus enabling situations associated with high infestations to be defined and avoided. Mr. Q. A. Geering (Cotton Research Station, Uganda) described a method used in Uganda for studying losses caused by cotton mirids. This utilizes single-row plots from which the pest is repelled by an insecticide, and is valuable in the case of mobile insects, for which ordinary plot methods break down. The results show how a plant which flowers over a considerable period can ultimately compensate for severe early damage, the real loss being in time rather than in yield.

Dr. W. R. Thompson (director of the Commonwealth Institute of Biological Control) outlined recent attempts to control two scale insects accidentally imported into Bermuda that have attacked the dominant shade tree there, a species of cedar that is unique to the island and, perhaps for that reason, highly susceptible to scale attack. Although some one and a half million individuals of forty species predatory or parasitic on scales were introduced, only two species, both Coccinellids, have become established. It appears that predators, as well as parasites, may have highly specific host-relationships. The Coccinellids now show signs of holding scale infestations below a level lethal to the surviving trees; but the lack of more striking success in a biological control operation on an island is surprising and emphasizes the need for further research if the results of such experiments are to be understood.

The principles underlying the biological control of weeds were discussed by Mr. J. R. Williams in a 
paper read by Dr. R. Mamet, both of the Department of Agriculture, Mauritius, where spectacular control of the introduced weed Cordia macrostachya has been effected by the leaf beetle, Schematiza cordiae. Essentially they involve exhaustive tests to show that the insect introduced is restricted to the weed to be controlled; the danger of the evolution of strains adapted to other, desirable plants after the elimination of the undesirable one seems slight, because the period during which intense selection of such strains would operate, following the rapid collapse of the weed population, would perforce be short.

In the discussion on pests of tropical cereesl erops, both the opening speakers stressed the need for special research, and the Conference endorsed this view. Dr. H. F. Barnes (Rothamsted Experimental Station) reviewed recently acquired records of the occurrence of certain important grain midges, and pointed out that the existence of biological races necessitates experimentation to show whether sorghum midge, which is a particularly serious pest, is a single species being spread with seed or a complex of species that have arisen independently. by convergent evolution. Mr. J. Bowden (Department of Agriculture, Gold Coast) said that damage by stemborers had been insufficiently appreciated and investigated because of the preoccupation of entomologists with cash crops. The two needs are critical taxonomic and biological studies of the groups concerned, and standardized ways of assessing infestation and damage; the methods developed in the Gold Coast, though simple, seem adequate.

Mr. G. V. B. Herford (director of the Pest Infestation Laboratory) spoke of the increasing realization of the magnitude of problems of stored-product pests, particularly those of the Colonial territories, where a number of research and advisory units, with which close liaison is being maintained, are now engaged. Notable technical developments include the extended use of the fumigation of bagged produce under gas-proof sheets, and greater provision for bulk storage of grain, either in silos utilizing circulatory fumigation or in sealed underground pits.

Dr. R. C. Fisher (Forest Products Research Laboratory, Princes Risborough) began the discussion on problems of forest entomology, and referred to another example of the establishment in a tropical region of a unit linked with a research institute in Britain, namely, the team studying bark boetles in West Africa. In this investigation and in those carried out at the Forest Products Research Laboratory, the emphasis is on the study of the biology of the insect and the relation of its attack to the history and condition of its host timber. Dr. F. T. Bird (Division of Forest Biology, Canada) gave an account of the use of virus diseases of European origin against two introduced sawflies. The virus, which has maintained an extreme virulence, has been artificially disseminated and gives rise to epizootics in succeeding years, being transmitted from year to year via the egg. The mortality is dependent on the population density and habits of the sawflies, and at low densities is greater in the spruce sawfly, the eggs of which are laid singly and whose larvæ feed singly.

Mr. W. V. Harris, who opened the discussion on termites, outlined the programme and progress of the Colonial Office Termite Research Unit, of which he is in charge. $\mathrm{H}_{\theta}$ mentioned some interesting points that have already emerged from the rapidly accumulating data on termite distribution and ecology in East Africa, and directed attention to the dispersa1 of injurious dry-wood species that is taking place around the tropics.

Mr. L. G. Putnam (Division of Entomology, Canada), in a paper read by $\mathrm{Mr}, \mathrm{A}$. B. Baird, discussed developments in grasshopper research and control in Canada. Grasshoppers, unlike locusts, are not strictly gregarious, and do not normally undertake long flights. Outbreak centres thus do not exist: overall abundance appears to depend on weather factors, now being analysed, and as the insects are univoltine and lay their eggs, which overwinter, in or adjacent to stubble, the intensity of damage is determined by the degree of juxtaposition of successive erops. Dr. B. P. Uvarov (director of the Anti-Locust Research Centre) dealt with the more complex dynamics of locust plagues, involving not only fluctuations in numbers but also changes in the extent of the populated area and qualitative differences between solitary and swarming populations. Quantitative studies of numerical fiuctuations and of their causes, especially biological ones, are now being pressed forward. A connexion has been demonstrated between large-scale swarm-displacements and movements of air masses, and the more mysterious movements that solitary adults are known to make are being studied. Recent work suggests that gregarious behaviour arises from conditioning, and persists even though the conditioning factors no longer operate.

Dr. C. H. N. Jackson (Tsetse Research Laboratory, Tanganyika) discussed the principal methods that have been used for controlling tsetse. These mostly depend on the selective destruction of some essential ferture of the fly's environment, such as the vegetation characterizing the favoured breeding site or affording protection against desiccation, or the animals that constitute the food supply or a principal element in it. Insecticides are effective, though rather expensive; their use leaves the environment unaltered and discloses the interesting likelihood that fly populations are unable to recover after reduction below a certain level. Some results of the empirical control methods have been explained by research on tsetse physiology and behaviour, but much more of such work is needed.

Dr. W. J. Hall (director of the Commonwealth Institute of Entomology), in opening a discussion on the supply and training of taxonomists, said that the existing provisions for taxonomic research and for the identification of insects and mites of economic importance are inadequate. Substantial increases in staff are needed in organizations connected with these activities, which are interdependent. A number of other suggestions for improving the situation were discussed, and a committe was set up to make recommendations.

A full report of the proceedings, including the resolutions adopted by the Conference, will be published later in the year by the Commonwealth Institute of Entomology, together with reviews of the progress of economic entomology in the Commonwealth countries since 1948.

During the Conference, delegates visited Rothamsted Experimental Station, the Silwood Park Field Station of the Imperial College of Science and Technology, London, and the Pest Infestation Laboratory of the Department of Scientific and Industrial Research. These visits, together with certain social occasions, provided the opportunity for informal discussion between entomologists from many widely separated countries that is so valuable a feature of these Conferences. 